\title{
Article \\ Real World Adherence to a Severely Energy Restricted Meal Replacement Diet in Participants with Class II and III Obesity
}

\author{
Gabrielle Maston ${ }^{1,2, *},+\left(\mathbb{D}\right.$, Hamid Reza Kahlaee ${ }^{3,4,5}{ }^{\oplus}$, Janet Franklin ${ }^{2}{ }^{(}$, Elisia Manson ${ }^{2}$, Alice A. Gibson ${ }^{6}(\mathbb{D}$, \\ Samantha Hocking $1,2,7\left(\mathbb{D}\right.$, Amanda Sainsbury ${ }^{8(\mathbb{D})}$ and Tania P. Markovic $1,2,7(\mathbb{D})$
}

1 The Boden Group, Charles Perkins Centre, The University of Sydney, Camperdown, NSW 2050, Australia; samantha.hocking@sydney.edu.au (S.H.); tania.markovic@sydney.edu.au (T.P.M.)

2 Metabolism \& Obesity Service, Royal Prince Alfred Hospital, Camperdown, NSW 2050, Australia; janet.franklin@health.nsw.gov.au (J.F.); Elisia.Manson@health.nsw.gov.au (E.M.)

3 Faculty of Medicine and Health, School of Pharmacy, The University of Sydney, Camperdown, NSW 2050, Australia; reza.kahlaee@sydney.edu.au

4 Department of Anaesthesia, The Children's Hospital at Westmead, Sydney, NSW 2145, Australia

5 Discipline of Child and Adolescent Health, Faculty of Medicine and Health, The University of Sydney, Camperdown, NSW 2050, Australia

6 Menzies Centre for Health Policy, School of Public Health, Faculty of Medicine and Health, The University of Sydney, Camperdown, NSW 2050, Australia; alice.gibson@sydney.edu.au

7 Sydney School of Medicine (Central Clinical School), Faculty of Medicine and Health, The University of Sydney, Camperdown, NSW 2050, Australia

8 School of Human Sciences, The University of Western Australia, Crawley, WA 6009, Australia; amanda.salis@uwa.edu.au

* Correspondence: gmas2269@uni.sydney.edu.au

+ Current address: Metabolism \& Obesity Service, Royal Prince Alfred Hospital, Missenden Rd, Camperdown, NSW 2050, Australia.

check for
updates

Citation: Maston, G.; Kahlaee, H.R.; Franklin, J.; Manson, E.; Gibson, A.A.; Hocking, S.; Sainsbury, A.; Markovic, T.P. Real World Adherence to a Severely Energy Restricted Meal Replacement Diet in Participants with Class II and III Obesity. Obesities 2022, 2, 8-20. https://doi.org/ 10.3390/obesities2010002

Academic Editor: Carmine Finelli

Received: 24 November 2021

Accepted: 7 January 2022

Published: 10 January 2022

Publisher's Note: MDPI stays neutral with regard to jurisdictional claims in published maps and institutional affiliations.

Copyright: (c) 2022 by the authors Licensee MDPI, Basel, Switzerland. This article is an open access article distributed under the terms and conditions of the Creative Commons Attribution (CC BY) license (https:// creativecommons.org/licenses/by/ $4.0 /)$.

\begin{abstract}
Severely energy-restricted diets (SERDs) are an effective treatment for obesity, however, adherence to such diets is often perceived as poor by healthcare professionals. This investigation evaluated adherence to a 12-week SERD in participants with class II and III obesity. Reported food consumption was compared against individualised SERD prescriptions. Body weight measures were obtained at baseline, 12 and 52 weeks. The data were analysed in three groups (i) the entire cohort $(n=26)$, (ii) completers $(n=13)$ and (iii) non-completers $(n=13)$. SERD prescription elements included (i) the number of meal replacement products; (ii) total protein; (iii) total energy intake; (iv) level of dietary energy restriction; (v) vegetable serves; (vi) water serves, and (vii) how much physical activity was performed. A generalised repeated-measures mixed-effects model was used to investigate if adherence to the program elements individually, or collectively, influenced weight loss. Completers had an average ( \pm SD) of $4549 \pm 748 \mathrm{~kJ}$ energy intake per day, resulting in a mean energy restriction of $62 \%$ compared to the $69 \%$ prescribed, indicating a degree of non-adherence. The percent weight changes for completers and non-completers were $-7.8 \pm 4.7 \%$ and $-1.6 \pm 2.6 \%$ at 12 weeks, and $-12.2 \pm 12.1 \%$ and $-1.8 \pm 3.2 \%$ at 52 weeks, respectively. Complete dietary adherence to a SERD may not be necessary to achieve a clinically relevant weight loss of $12 \%$ at 52 weeks, if energy is restricted by at least $62 \%(\sim 4600 \mathrm{~kJ}$ per day) relative to requirements.
\end{abstract}

Keywords: obesity; diet; reducing; management; low-energy liquid diet; very-low-energy diet

\section{Introduction}

Obesity is an epidemic that affects 2.1 billion people worldwide [1]. The prevalence and severity of obesity continue to rise globally, increasing the burden of disease [2-4]. Obesity is a disease that is associated with other chronic health conditions, such as cardiovascular disease [5,6], type 2 diabetes [7,8], gall bladder disease [9], kidney disease [10], obstructive sleep apnea [11], cancer [12], depression [13], infertility [14] and osteoarthritis [15]. Intentional weight loss dose-dependently reduces the risk factors associated with 
the development and progression of all obesity-related chronic health conditions [16-20]. Energy restriction remains the only intervention paradigm that has been shown to increase lifespan in mammals and delay age-related disease [21,22]. Effective weight loss treatments that induce energy restriction are necessary to curb the burden of the disease.

The best available non-surgical, non-pharmacological treatment for obesity is a "severely energy-restricted diet" (SERD) [23,24]. A SERD provides an estimated energy restriction of at least $65 \%$ relative to the estimated total energy expenditure [25]. For people with class II obesity (i.e., a body mass index [BMI] $\geq 35.0 \mathrm{~kg} / \mathrm{m}^{2}$ and $<40.0 \mathrm{~kg} / \mathrm{m}^{2}$ ) and class III obesity (i.e., a BMI $\geq 40.0 \mathrm{~kg} / \mathrm{m}^{2}$ ), a SERD can encompass both very-low-energy diets (VLEDs), delivering 2100 to $3400 \mathrm{~kJ}$ (500 to $800 \mathrm{kcal}$ ) per day, and low-energy diets, delivering 4200 and $5000 \mathrm{~kJ}$ (1000 to $1200 \mathrm{kcal})$ per day [26,27], because of the level of energy restriction created. SERDs can be prescribed as a total meal replacement diet with the sole use of meal replacement products, which may also include a prescribed amount of additional low starch and low energy vegetables, and unlimited amounts of sugar-free and milk-free tea and coffee [28]. SERDs can also be prescribed as a partial meal replacement diet, which involves using one to three meal replacement products per day to replace food-based meals, plus a prescribed food-based meal for any meal not replaced [29]. SERDs are typically prescribed for a duration of 4 to 12 weeks [28].

While patients seeking weight management treatment can benefit from the prescription of a SERD, a recent survey of Australian healthcare professionals revealed they are only prescribed to a median of $7 \%$ of patients seeking weight management treatment [30]. Multiple barriers were found to prescribing a SERD, including perceived poor dietary adherence (i.e., the extent to which a person's behaviour corresponds with the recommendations that were made following discussion between the healthcare professional and the patient [30]). Adherence to a SERD, to our knowledge, has not been quantified in participants with class II and III obesity and obesity-related comorbidities.

When reviewing the literature, we identified one study that explored dietary intake during a partial meal replacement diet in comparison to an energy equivalent food-based diet in a cohort of participants that had a BMI classified as overweight or obese (i.e., 27 to $40 \mathrm{~kg} / \mathrm{m}^{2}$ ) and excluding those with chronic health conditions (i.e., uncomplicated overweight or obesity) [31]. This provides little indication of the effects of such diets for people with class II and III obesity with multiple comorbidities (i.e., complicated obesity), which may pose additional challenges to dietary adherence. In the aforementioned study [31], dietary adherence was quantified and reported concerning nutritional adequacy, reporting quantities of macronutrients and micronutrients consumed compared to the foodbased control, rather than in comparison to the prescribed diet. Information on nutritional adequacy is useful for determining the safety of such diets; however, it does not provide any guidance on a minimum level of dietary adherence required to achieve weight loss outcomes, nor does it permit the identification of dietary prescription elements that are the key factors contributing to adherence and the reported weight loss outcomes.

In another investigation identified in the literature [32], adherence was quantified concerning the length of time a participant with BMI $\geq 30 \mathrm{~kg} / \mathrm{m}^{2}$ was able to sustain a VLED, to a maximum of up to 26 weeks. Low, moderate, and high adherence were defined as following the diet for 1 to 12 weeks, 13 to 20 weeks, and 21 to 26 weeks, respectively. The greater the length of time adhering to a VLED, the greater the weight loss and improvements in health profiles observed [32]. The high adherence group had a greater number of participants achieving 15\% weight loss. While this information is useful to help determine the optimal length of time to follow a SERD, it does not indicate how well participants adhere to the prescribed dietary program to achieve the associated weight loss outcomes and health improvements.

In a qualitative study, participants in a cohort of 30 participants from the Counterbalance study [33] were interviewed to determine dietary acceptably during a VLED, as well as factors that were perceived to influence dietary adherence, for example, hunger, the environment and social support [34]. This provided no indication as to whether the VLED 
was strictly adhered to, and if participants consumed any non-prescribed items during the investigation.

In an earlier investigation, we qualitatively documented dietary adherence to a SERD [35]. Factors that facilitate or create barriers to dietary adherence were thematically identified, including the presence of product palatability issues, unrealistic weight-loss expectations, socio-economic disadvantage, and experiences of weight-related stigma that challenged healthful behaviours [35]. This study, however, did not quantify adherence objectively. Weight loss can be used as a surrogate measure of adherence, however, through these means it does not reveal the level of energy restriction needed to achieve the weight loss observed among participants.

In our earlier investigation and in clinical practice, we have observed that adherence to a SERD is highly variable, as are weight loss outcomes. This study measured and quantified adherence during participation in a SERD group program for people with obesity-related comorbidities and class II and III obesity (BMI $\geq 35 \mathrm{~kg} / \mathrm{m}^{2}$ ) at a publicly-funded tertiary obesity clinic.

\section{Materials and Methods}

This prospective observational study was conducted at a tertiary referral hospital, at the outpatient Metabolism and Obesity Service. People with class II and III obesity (i.e., $\mathrm{BMI} \geq 35 \mathrm{~kg} / \mathrm{m}^{2}$ ) and obesity-related comorbidities were prescribed an individualised SERD for weight management and were invited to participate in the research project (see File S1 in the Supplementary Materials). The inclusion criteria included any person who was referred to the outpatient Metabolism and Obesity Service and triaged into the Complex Obesity Service. To be triaged into the Complex Obesity Service, a person must live in a rural or regional area outside of the Sydney City region, or must have a BMI $\geq 55 \mathrm{~kg} / \mathrm{m}^{2}$, or must have severe metabolic disease requiring accelerated medical attention. The exclusion criteria for participation in this study were the presence of absolute contra-indications to the use of a meal replacement VLED, which include pregnancy, presence of severe or systemic organ disease (i.e., severe renal or hepatic disease, unstable angina pectoris, recurrent cerebrovascular accident, or recent cardiac infarction), a clinically diagnosed eating disorder, or major psychiatric disease [36].

All participants gave their informed consent to participate in the study. This study was approved by the Ethics Review Committee Royal Prince Alfred Hospital of the Sydney Local Health District on 7th September 2017 (LNR/18/CRGH/50).

The study's primary aim was to measure adherence to a 12-week meal replacement SERD and the accompanying fortnightly group program, which included the prescription of meal replacement products, supplemental and food-based protein, low starch and low energy vegetables, a minimum target of water intake, and exercise. Adherence was determined by quantifying the amount of food and beverage consumption, and exercise performed, against the prescribed quantities. Data on food intake and exercise were obtained using two self-reported food and exercise diaries that were to be completed daily for 14 days during the first two weeks of the diet and between the third and 12th week of the diet. The diaries were provided at the start of the program. The first food and exercise diary from participants were collected at the second group appointment (i.e., after patients had been on the diet for two weeks), and the second food and exercise diary from participants were collected at the last group appointment, on the 12th week. The completion of the food and exercise diary involved documenting all non-prescribed and prescribed foods and beverages consumed, as well as the mode and amount of exercise performed. The diary was considered complete if at least 11 of the 14 of the days were recorded in two weeks. The secondary aim was to measure weight loss from baseline to the end of the 12-week SERD program and to the 52-week follow-up time point.

When patients were triaged to the Complex Obesity Service, they were advised that their initial treatment would be a SERD for which they would receive education and support with a group program. The group program consisted of a one-hour group 
appointment undertaken every 2 weeks for 12-weeks. At the first group appointment, participants were approached by the lead researcher (GM) and invited to participate in the research project, at which time written consent was obtained. The groups were facilitated by a trained healthcare professional (dietitian) and consisted of a minimum of two and a maximum of seven participants. The group appointments were structured to include nutrition and behavioural lifestyle coaching and made use of psychological techniques such as motivational interviewing [37]. All participants were provided with recommendations for exercise. The exercise recommendations included performing a regular movement of any type for at least $30 \mathrm{~min}$ every day. Suggested suitable exercise modes were provided during the group discussions and included walking, low impact body weighted exercise or participating in aqua aerobics classes. After the 12-week group program, participants were provided with a monthly appointment with a trained healthcare professional (dietitian or nurse) for the remaining 52 -weeks.

When participants did not attend their scheduled group or individual appointment, the lead researcher (GM) attempted to re-engage the participant by a telephone call. During this phone call, if the participants reported adhering to the SERD, another group appointment was offered. If the participant reported significant challenges with adherence to the SERD, the participant was offered an individualised appointment for the subsequent month instead of returning to the group program. Support was also provided during the call on how to transition to a partial meal replacement SERD, or to begin a healthy eating plan where necessary. Self-reported weight was also obtained, and participants were encouraged to return their food and exercise diary at the following appointment.

All participants were initially prescribed a SERD with supplemental protein that aimed to achieve a set protein target of $0.8 \mathrm{~g}$ per kilogram of an adjusted ideal body weight at a BMI of $25 \mathrm{~kg} / \mathrm{m}^{2}$. A target of $0.8 \mathrm{~g}$ per kilogram protein approximates the mean recommended daily intake of protein for men ( $0.75 \mathrm{~g}$ per kilogram of ideal body weight) and women ( $0.84 \mathrm{~g}$ per kilogram of ideal body weight) needed for health [38]. The equation used to determine the appropriate protein intake for participants was calculated using the following formula [39]:

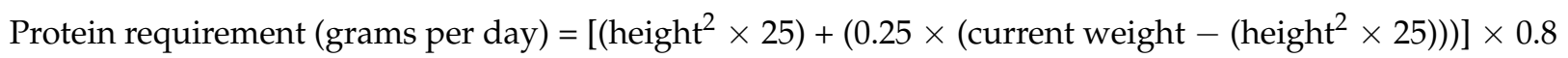

The calculated protein requirement was used to determine the number of meal replacement products and grams of supplemental protein to prescribe. Each meal replacement contained approximately $20 \mathrm{~g}$ of protein, with three meal replacements prescribed as a minimum to follow a common Western-style pattern of eating: breakfast, lunch, and dinner. When protein requirements exceeded $60 \mathrm{~g}$ per day, participants were given a choice of the number of meal replacement products they preferred to consume in combination with supplemental protein or a pragmatic amount of food-based protein. A list of suitable brands of meal replacement products and protein powder and suitable food-based protein options was provided.

All participants were prescribed five serves of low starch and low energy vegetables (one serve defined as 1 cup of salad vegetables, or half a cup of cooked vegetables [40]), $2 \mathrm{~L}$ of water (8 cups of $250 \mathrm{~mL}$ serve) and $4 \mathrm{~g}$ of oil or fat equivalent per day.

The energy content of the diet was determined by the overall protein prescription. The greater the amount of protein prescribed, the greater the prescribed energy content. The energy content of the diet was calculated by summing the kilojoule content of the number of prescribed meal replacements, supplemental protein, and added fat.

When the 12-week meal replacement SERD period ended, or when the participant expressed challenges with continuing to follow the prescribed diet, the prescription was adjusted to a partial meal replacement SERD with a daily energy intake prescription below a threshold of $<5000 \mathrm{~kJ}(1200 \mathrm{kcal})$. This consisted of the removal of one meal replacement product and all supplemental protein in exchange for a prescribed high-protein low-carbohydrate meal. Participants could choose from a selection of protein-rich-food sources in prescribed quantities (approximately $300 \mathrm{~g}$ white fish, $200 \mathrm{~g}$ chicken, $200 \mathrm{~g}$ pork, 
$100 \mathrm{~g}$ of lean red meat, $100 \mathrm{~g}$ oily fish, or three eggs) and a mixture of low starch and low energy vegetables from a list provided. The prescribed meal approximated an energy content of 837 to $1050 \mathrm{~kJ}$ ( $200 \mathrm{to} 250 \mathrm{kcal}$ ) and 20 to $30 \mathrm{~g}$ of protein. Participants remained on this partial meal replacement diet until they expressed the desire to discontinue the use of meal replacement products altogether. Participants were then encouraged by the healthcare professional during the individual appointments to eat healthy meals and maintain a regular exercise routine.

\section{Data Analysis}

All food records that were returned were analysed, including those that were incomplete. The food records were analysed using food nutrient data in the Australian Food Composition Database (NUTTAB) [41]. When food quantities were not stated, a standard serving size, as determined from the Database of NUTTAB, was used to quantify the meal's energy and protein composition.

The energy content of the non-prescribed and prescribed low starch and low energy vegetables was not quantified. This approach was taken to minimise the burden placed on participants in recording individual portions of singular vegetables within mixed meals.

All dietary elements of the SERD program prescription and additional food or drinks consumed were quantified in serves and reported in kilojoules. The seven prescribed SERD program elements were quantified by assessing how closely each participant adhered to the following elements of the prescribed program per day: consumption of (i) meal replacement products; (ii) total protein; (iii) total energy intake; (iv) level of dietary energy restriction; (v) vegetable serves; (vi) water and (vii) how much physical activity was performed. An average daily intake was calculated per individual per food record, to account for the differences in food record entries among days in the food record.

The prescribed elements were compared against the reported intake of food and drink and the reported amount of exercise performed by using a paired $t$-test. The data for each of the program elements were then converted into a measure of adherence, calculated as a percentage of what was prescribed, which was subsequently used in a linear mixed-effects model. A mean total adherence score was also calculated for each participant by finding the average of all seven-program element adherence scores. The mean total adherence score was then reviewed separately within the model as an independent continuous variable.

The measurement of the mean percent energy restriction for each participant was calculated via the use of the Harris-Benedict equation (activity factor of 1.3, indicating light activity) for estimating individual energy requirements [42] and the reported prescribed energy intake using the following formula:

Mean percent energy restriction $=(($ estimated daily energy requirement prescribed energy intake)/estimated daily energy requirement) $\times 100$

A linear mixed model was then performed to determine if adherence to any of the seven prescribed dietary elements individually or collectively influenced weight loss. To do this a repeated measures mixed-effects model was used. In the model, the effect of individual confounding factors such as age, sex, the number of comorbidities, and the presence of type 2 diabetes was also reviewed.

Adherence to the SERD program was also measured by capturing weight loss data. If the participant attended a group or individual appointment in person, a body weight measurement was obtained. If the participant did not attend in-person but engaged in a phone call, a self-reported weight was used. If there was no data available from in-person or self-reported weight, then a last known bodyweight measured carried forward method was used to calculate the total weight loss achieved at the 12-week and 52-week timepoint. The data were then analysed in three ways, (i) as the entire group $(n=26)$, (ii) completers $(n=13)$ and (iii) non-completers $(n=13)$. Completers were defined as participants who returned at least one complete food and exercise record and reported following a SERD (be it a total meal replacement diet or partial meal replacement diet) for the full 12-week 
duration. Non-completers were participants who did not meet the described criteria to be classified as a completer.

The weight loss results from the entire cohort, completers, and non-completers, were then compared at the end of the 12-week SERD program and 52-week follow up. A linear mixed-effects model was used to determine if the weight losses of the two groups (completers and non-completers) were significantly different from each other. The dependant variable for this analysis was percent loss in body weight, which was analysed as a continuous variable. The model was fit by considering the effects of time (12 and 52 weeks) and grouping (completers and non-completers).

All statistical analyses were conducted using R Statistical Software Core Team (2020). (Version 4.0.0, R Foundation for Statistical Computing, Vienna, Austria, www.R-project. org/; accessed on 24 February 2021).

\section{Results}

Of the 26 participants enrolled, $13(50 \%)$, deemed completers, returned the initial 2-week daily food and exercise record. Only seven (54\%) of the participant completers also returned a second food and exercise record for the remaining 3 to 12 weeks of the program.

Figure 1 provides a breakdown of the group of participant completers and noncompleters and the points at which participants dropped out of the SERD program. Eleven of the 13 completers attended the SERD group program in person for 12 weeks. The remaining two participants did not attend in-person SERD group sessions at week six and were re-engaged via telephone (during which self-reported body weight measures were obtained). These two participants followed a partial meal replacement SERD to complete the 12-week program.

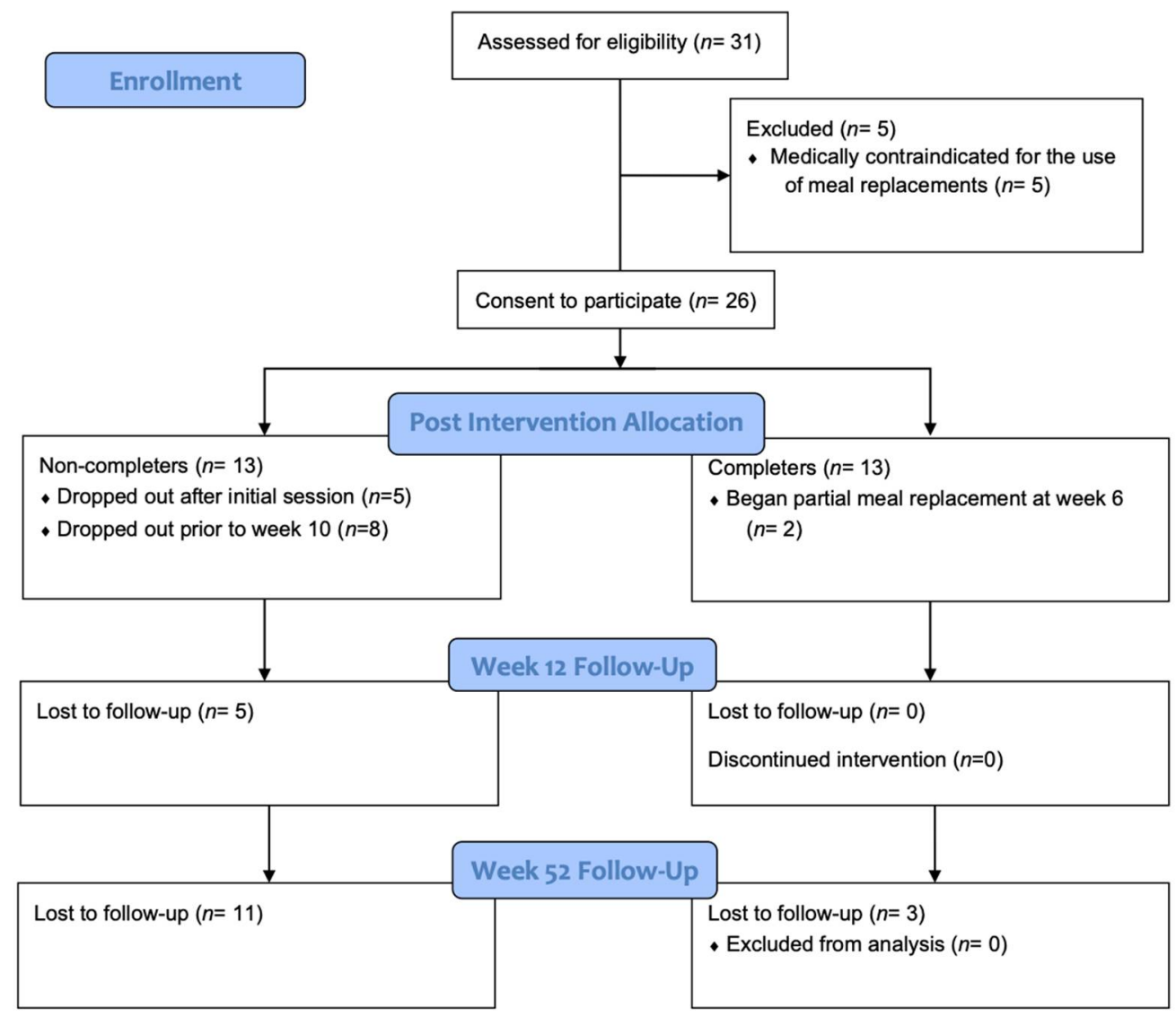

Figure 1. The breakdown of non-completers and completers and points of SERD program dropout. 
Of the 13 non-completers, five did not attend the weight loss service after their initial SERD group program session and were not contactable via telephone, so no further data were collected. Eight non-completers dropped out before 10 weeks. All of the eight noncompleters discontinued the use of meal replacement products before program dropout. One non-completer attended the weight loss service at week 12 for a body weight measure. One non-completer attended the weight loss service in person for a body weight measure at week 52, and one non-completer was contactable via a phone call to obtain a self-reported weight measure. Seven non-completers attended at least one, and a maximum of three, individual in-person appointments with a healthcare professional at the weight loss service (when actual weight measures were obtained) between 24 and 52 weeks of the follow up period. The actual weight measures taken outside of the 12- and 52-week time points were used in the data analysis when a last known bodyweight carried forward method was used.

Participant characteristics for the entire cohort of 26 participants, 13 completers and 13 non-completers can be seen in Table 1 . The 13 completers included those who switched to a partial meal replacement at 6 weeks. The attendance rate for the entire cohort of 26 participants was $47 \%$, which is an average \pm SD of $3.3 \pm 1.8$ in-person SERD group sessions out of a possible 7 in the 12 weeks. The attendance rate for completers was $63 \%$, with participants attending on average \pm SD $4.4 \pm 1.6$ group sessions, and for the group of non-completers, the attendance rate was $28 \%$ ( $2.0 \pm 1.2$ group sessions).

Table 1. Participant characteristics at baseline and weight loss outcomes at 12 and 52 weeks displayed as the entire group, completers, and non-completers.

\begin{tabular}{|c|c|c|c|c|}
\hline & $\begin{array}{l}\text { Entire Group } \\
\quad(n=26) \\
\text { Mean } \pm \text { SD }\end{array}$ & $\begin{array}{l}\text { Completers } \\
(n=13) \\
\text { Mean } \pm \text { SD }\end{array}$ & $\begin{array}{l}\text { Non-Completers }(n=13) \\
\text { Mean } \pm \text { SD }\end{array}$ & $\begin{array}{l}p \text {-Value for the Mean Difference between Completers and } \\
\text { Non-completers } \\
(p<0.05)\end{array}$ \\
\hline Age (years) & $44.5 \pm 10.8$ & $42.5 \pm 10.9$ & $46.4 \pm 10.9$ & 0.377 \\
\hline No. of obesity related comorbidities a & $4.7 \pm 2.2$ & $3.7 \pm 2.2$ & $5.6 \pm 1.8$ & $0.023 *$ \\
\hline Mean BMI $\left(\mathrm{kg} / \mathrm{m}^{2}\right)$ & $53.8 \pm 11.1$ & $55.0 \pm 10.5$ & $52.6 \pm 11.5$ & 0.586 \\
\hline Baseline body weight $(\mathrm{kg})$ & $151.3 \pm 33.2$ & $150 \pm 35.1$ & $152.6 \pm 32.5$ & 0.841 \\
\hline Mean weight change at 12 weeks $(\%)$ & $-4.7 \pm 4.9$ & $-7.8 \pm 4.7$ & $-1.6 \pm 2.6$ & $0.001 *$ \\
\hline Mean weight change at 12 weeks $(95 \% \mathrm{CI})$ & $(-6.6,-2.7)$ & $(-10.6,-4.9)$ & $(-3.1,0.0)$ & - \\
\hline Percentage of participants with self-reported data at 12 weeks $(n)$ & $34.6(9)$ & $15.4(2)$ & $53.9(7)$ & - \\
\hline Percentage of participants with bodyweight carried forward data at 12 weeks $(n)$ & $19.2(5)$ & $0.0(0)$ & $38.5(5)$ & - \\
\hline Mean weight change at 52 weeks $(\%)$ & $-7.0 \pm 10.2$ & $-12.2 \pm 12.1$ & $-1.8 \pm 3.2$ & $0.006^{*}$ \\
\hline Mean weight change at 52 weeks $(95 \% \mathrm{CI})$ & $(-11.1,-2.9)$ & $(-19.5,-4.9)$ & $(-3.7,0.2)$ & - \\
\hline Percentage of participants with self-reported data at 52 weeks $(n)$ & $15.4(4)$ & $23.0(7)$ & $7.7(1)$ & - \\
\hline Percentage of participants with bodyweight carried forward data at 52 weeks $(n)$ & $53.8(14)$ & $23.0(3)$ & $42.3(11)$ & - \\
\hline
\end{tabular}

Table legend: No., number; SD, standard deviation; CI, 95\% confidence interval; * $p$-value of $<0.05$ denoting statistical significance; ${ }^{a}$ comorbidities, including type 2 diabetes, cardiovascular disease, hypertension, hypercholesterolemia, depression, osteoarthritis, asthma, obstructive sleep apnoea, reflux, and asthma.

The number of obesity-related co-morbidities differed between the groups of completers and non-completers. The group of non-completers versus completers had a higher percentage of participants with hypertension (53.8\% vs. $38.5 \%)$, depression $(61.5 \%$ vs. $46.2 \%)$, arthritis (53.8\% vs. $30.8 \%$ ), reflux (53.8\% vs. $15.4 \%$ ) and hypercholesterolemia (38.5\% vs. $15.4 \%$ ). Both groups had $46.2 \%$ of participants with type 2 diabetes. The group of completers versus non-completers had a higher percentage of participants with asthma (38.5\% vs. $23.1 \%$ ) and obstructive sleep apnoea (61.5\% vs. 53.8\%).

The seven quantified SERD program elements can be viewed in Table 2 . The repeated measures linear mixed-effects model results demonstrated that among the seven program elements, all but one had a significant effect on weight loss. The program element that did not reach significance was total energy intake F-value $=0.065(p=0.800)$. The six remaining individual program elements demonstrated that the greater the degree of adherence, the greater the weight loss observed as a continuous variable (number of meal replacements F-value $=58.8(p<0.001)$; energy restriction F-value $117.6(p<0.001)$; protein F-value $=6.8(p=0.015)$, vegetable consumption F-value $=12.5(p=0.002)$, water consumption F-value $=20.8(p<0.001)$ and exercise performed F-value $=185.8(p<0.001))$. 
Table 2. The comparison of the reported amount of food and drink consumed, and exercise performed, in comparison to the prescribed SERD as a determinant of adherence.

\begin{tabular}{|c|c|c|c|c|c|c|c|}
\hline & $\begin{array}{l}\text { Prescription for } \\
\text { the Entire Group } \\
(n=26) \\
\text { Mean } \pm \text { SD }\end{array}$ & $\begin{array}{c}\text { Prescription for } \\
\text { Non-Completers } \\
(n=13) \\
\text { Mean } \pm \text { SD }\end{array}$ & $\begin{array}{c}\text { Prescription } \\
\text { for Completers } \\
(n=13) \\
\text { Mean } \pm \text { SD }\end{array}$ & $\begin{array}{l}\text { Reported Food and } \\
\text { Exercise Amounts for } \\
\text { Completers }(n=13) \\
\text { Mean } \pm \text { SD }\end{array}$ & $\begin{array}{l}\text { Difference between } \\
\text { Prescribed and } \\
\text { Reported Amounts for } \\
\text { Completers } \\
\text { Mean } \pm \text { SD }\end{array}$ & $\begin{array}{l}p \text {-Value for the Mean Difference between } \\
\text { Prescribed and Reported Food and } \\
\text { Exercise Quantities for Completers } \\
(p<0.05)\end{array}$ & $\begin{array}{l}\text { Mean Percent } \\
\text { Adherence for } \\
\text { Completers (\%) }\end{array}$ \\
\hline Mean no. of MR & $4.0 \pm 4.3$ & $4.1 \pm 1.0$ & $3.8 \pm 0.6$ & $3.1 \pm 0.5$ & $-0.8 \pm 0.2$ & $0.001 *$ & $82.6 \pm 21.2$ \\
\hline Protein (g) & $96.4 \pm 15.6$ & $97.1 \pm 17.4$ & $95.7 \pm 14.3$ & $76.7 \pm 16.8$ & $-19.0 \pm 6.1$ & $0.005 *$ & $81.1 \pm 17.4$ \\
\hline $\begin{array}{l}\text { Energy intake (kJ) } \\
\text { [kcal] }\end{array}$ & $\begin{array}{l}3774.8 \pm 581.6 \\
{[903.1 \pm 139.1]}\end{array}$ & $\begin{array}{l}4639.4 \pm 1761.9 \\
{[1108.8 \pm 421.1]}\end{array}$ & $\begin{array}{l}3700.2 \pm 444.3 \\
{[884.4 \pm 106.2]}\end{array}$ & $\begin{array}{c}4549.3 \pm 747.7 \\
{[1087.3 \pm 178.7]}\end{array}$ & $\begin{array}{l}849.1 \pm 241.2 \\
{[202.9 \pm 57.6]}\end{array}$ & $0.002 *$ & $125.0 \pm 27.5$ \\
\hline $\begin{array}{l}\text { Mean percent energy } \\
\text { restriction }(\%)\end{array}$ & $69.2 \pm 6.3$ & $68.9 \pm 8.6$ & $69.2 \pm 6.5$ & $62.2 \pm 7.7$ & $-7.3 \pm 6.9$ & $0.007 *$ & $62.2 \pm 7.7$ \\
\hline $\begin{array}{l}\text { Mean serves of } \\
\text { vegetables (Salad and } \\
\text { cooked vegetables) }\end{array}$ & $5.0 \pm 0.0$ & $5.0 \pm 0.0$ & $5.0 \pm 0.0$ & $3.3 \pm 1.9$ & $-1.7+0.5$ & $0.004 *$ & $66.1 \pm 38.5$ \\
\hline Mean litres of water & $2.0 \pm 0.0$ & $2.0 \pm 0.0$ & $2.0 \pm 0.0$ & $1.6 \pm 1.0$ & $-0.4+1.0$ & 0.160 & $79.8 \pm 50.2$ \\
\hline $\begin{array}{l}\text { Mean duration of } \\
\text { exercise (minutes) }\end{array}$ & $30.0 \pm 0.0$ & $30.0 \pm 0.0$ & $30.0 \pm 0.0$ & $22.9 \pm 22.4$ & $-7.1+6.2$ & 0.263 & $76.2 \pm 74.8$ \\
\hline
\end{tabular}

Table legend: SD; standard deviation, MR; meal replacement, ${ }^{*} p$-value of $<0.005$ denoting significance.

When analysing the data using the mean total adherence score, it was found that the greater the overall adherence to the entire prescribed diet program (seven program elements), the more successful the participant was in losing weight, with F-value $=12.1$ $(p<0.001)$. In this analysis, having the comorbidity of type 2 diabetes was found to be a significant confounding factor, with F-value $=27.3(p<0.001)$, indicating that participants with type 2 diabetes lost more weight than those without.

Table 1 contains the weight loss results of the entire group, group of completers and non-completers. The weight loss for the group of completers and non-completers was compared at 12 and 52 weeks. A significant difference was found at the 12-week and 52-week time point for weight loss between the two groups.

\section{Discussion}

Healthcare professionals report perceived poor dietary adherence to SERDs by people with obesity as a barrier to prescription [30]; however, adherence to individual elements of a SERD program amongst people with class II and III obesity has, to our knowledge, never been quantified. In this investigation, we measured adherence to a SERD in a small group of participants with class II and III obesity by comparing the prescribed SERD program elements against reported amounts of food and beverages consumed and the reported amount of exercise performed according to contemporaneous food and exercise records. These findings may guide clinicians on how to adapt SERD programs to facilitate adherence, by demonstrating a pragmatic level of adherence that may be required to achieve clinically significant weight loss, and thus improve health outcomes.

While participants deemed completers were not adherent to all seven SERD program elements, we have demonstrated that the greater the adherence to the prescribed SERD program, the greater the weight loss achieved. In our study completers who had followed a SERD for a duration of 12 weeks had a 12.2\% loss in body weight when measure at 52 weeks. This demonstrates that complete adherence may not be necessary to achieve a clinically relevant weight loss of $10 \%$ or more of initial body weight at one year. Guidelines from Australia, the United States of America and other countries recommend that a $10 \%$ reduction in body weight is an appropriate weight loss target for people with class III obesity, as this is associated with decreased health risk and improved metabolic health [43-46].

The number of meal replacement products prescribed was significantly different from the amounts that were reportedly consumed, with participants under-consuming in this dietary element. We suspect that the under-consumption of meal replacement products is due to the consumption of other non-prescribed food items. For example, participants recorded consuming food with a high energy value such as cheese, olives, nuts, and crackers during the diet, which tended to displace the consumption of some of the meal replacements and protein prescribed. 
There was a significantly higher energy intake consumed in comparison to that prescribed. It was also found that 'energy intake' as an individual program element was not associated with weight loss in the linear mixed-effect model. We suspect that the single program element of 'energy intake' was not associated with weight loss because it did not reach a high enough threshold to impact weight loss. It has been previously demonstrated that $13,498 \pm 4753 \mathrm{~kJ} /$ day $(3326 \pm 1131 \mathrm{kcal} /$ day $)$ for men and 11,489 $\pm 4962 \mathrm{~kJ} /$ day $(2746 \pm 1186 \mathrm{kcal} /$ day) for women with class II and III obesity is the average energy intake during weight stabilisation [47]. Thus, it is likely that a group mean energy intake of $4549 \mathrm{~kJ}$ (1088 kcal) per day would still be low enough to be below a threshold to observe weight loss.

The group of completers consumed a mean of $4549 \mathrm{~kJ}$ (1088 kcal) per day during the 12-week program, which was higher than the prescribed diet, yet resulted in a mean weight loss of approximately $12 \%$ at 52 weeks, which is considered clinically relevant for reducing the health risk factors leading to obesity-related comorbidities [17,48,49]. It seems that a mean energy restriction of approximately $62 \%$, as opposed to $69 \%$, may allow a prescription of a slightly higher energy intake of $\sim 4600 \mathrm{~kJ}$ (1100 kcal) during a SERD. This higher energy intake prescription and hence lower energy restriction may be an upper threshold and a more useful pragmatic target to set for this group to achieve clinically relevant weight loss. Although this appears to be a small $7 \%$ difference, it can allow some flexibility in dietary intake assisting with adherence without compromising results. This knowledge could prove valuable to healthcare professionals who may want to adapt SERD prescriptions to higher energy thresholds to improve adherence amongst their patients from the outset. This may provide a strategy for retaining more people on a SERD program for the entire 12-week program duration and achieving clinically relevant weight loss.

Most participant completers did not meet adherence to the prescribed vegetable intake. The prescription of vegetables during a meal replacement SERD is not routinely practised in clinical trials [28]. Our results demonstrated that the greater the adherence to the prescription of the consumption of vegetables, the greater the weight loss, which suggest that weight loss may be aided by the addition of vegetables. The prescription of vegetables is useful because there is not a single total meal replacement product on the Australian market that provides all of the nutrients required for complete nutrition [39]. The addition of vegetables to the SERD prescription assists in overcoming this nutrient gap. Notably, vegetables provide a source of fibre, which can alleviate or prevent constipation, which is a common adverse effect of such diets [50]. Prescribing vegetables as part of a SERD may also assist with the social aspects of eating, allowing the person to partake in a low-energy meal containing various vegetables that allow them to feel like they are participating in eating with others. It may also improve the quality of a person's diet and provide a learning experience on how to cook and prepare vegetables in a palatable way, at least in theory.

Partial adherence to the prescribed vegetable intake may have been due to the inconvenience of cooking and preparing vegetables, especially when no other food item is prepared to complement the vegetables as a meal. A low vegetable intake may also reflect poor habitual eating patterns, whereby vegetables are not normally eaten. A previously published paper has demonstrated that consumption of vegetables is generally extremely low, approximately one serving of vegetables per week, amongst people with class II and class III obesity [51,52]. Suboptimal vegetable intake is a global issue. A meta-analysis of data from 187 countries' national nutrition surveys found that the mean global intake of vegetables for all adults is $208 \mathrm{~g}$ per day [53], which equates to approximately 2.5 serves of vegetables per day. A high vegetable intake seems to protect people from weight gain and obesity; therefore, it is perhaps unsurprising that vegetable intake is low in the participants investigated in the current study $[54,55]$.

Non-completers had a greater number of obesity-related comorbidities present compared to completers and had a greater percentage of participants who had depression $(61.5 \%$ vs. $46.2 \%)$. It is possible that the greater number of medical conditions imposed additional challenges. Due to this, other aspects of healthcare may have been prioritized 
over participation in the dietary program. Medical conditions can impose attention, time and financial costs that may interfere with program participation. Among the group of completers (with fewer medical conditions), the presence of type 2 diabetes could have been a motivating factor for dietary adherence to improve their medical condition and achieve remission [17].

The findings from this study show that participant completers, although not completely adherent to the dietary recommendations, continued to lose weight throughout the 52-week follow up period to achieve clinically relevant weight loss at 52-weeks. We suspect that weight loss continued after the 12-week program due to the ongoing and regular individual appointments with the healthcare professional.

In contrast, at 52 weeks the group of non-completers achieved a weight loss of approximately $2 \%$, which is not at a threshold considered clinically relevant. This indicates that although data on dietary intake for non-completers was not captured, it is likely they were non-adherent to the SERD. This is a group of participants that may require more support and further investigation of factors that may have contributed to the SERD program dropout.

There are limitations to this investigation that may constrain the generalisability of the results. Primarily, the number of study participants is small; conducting a more extensive study with a randomised design and a larger number of study participants is needed to confirm our results. The small sample size and the use of the last bodyweight measured carried forward method may not be the true bodyweight of the participant at 52 weeks with weight regain a common occurrence after weight loss interventions [56]. We suspect that participants with missing data are those who did not experience weight loss at the outset of the dietary intervention, had medical conditions that interfered with participation in the program, or experienced other significant barriers to program participation.

Similarly, self-reported body weights were also used in the data analysis, and this may also affect results, as it is well-known people with overweight and obesity under-report body weight $[57,58]$. Under-reporting may also exist in the dietary intake data captured within the food and exercise records. It is also well established that people under-report dietary intake [59]. Similarly, not all food entries in the food and exercise records contained the serving sizes of food and drink consumed, and thus a standard serving size was used within the analysis. This estimation may not provide a true reflection of the actual volumes of food consumed.

An observational study design also has an inherent bias, notably because participants in this study self-selected to join the study and the dietary treatment intervention was known to participants. Participants enrolled in the study may have had a higher level of motivation for weight loss because they had been referred to a tertiary weight loss service by their treating physician. On the other hand, there was a lack of data obtained from the group of non-completers, introducing reporting bias.

\section{Conclusions}

Among those who completed the 12-week SERD, we have demonstrated that absolute adherence does not appear to be necessary to achieve clinically relevant weight loss at 1 year. Suboptimal adherence to a SERD program was experienced by participants with class II and III obesity. Half of the participants studied did not complete the 12-week program and the remaining participants, who completed the program, were not completely adherent to the program prescription. A mean upper energy intake threshold of $62 \%$ energy restriction with an energy intake of $\sim 4600 \mathrm{~kJ}$ (1100 kcal) per day appears to still allow participants with class II and III obesity (BMI $\geq 35 \mathrm{~kg} / \mathrm{m}^{2}$ ) to achieve an average of $12 \%$ loss of body weight at 1 year, within the context of a publicly funded tertiary obesity clinic. Moreover, the greater the adherence to the seven program elements of the SERD, the greater the weight loss achieved. If patients are apprised of this finding, they may be more motivated to follow the dietary prescription more closely, which may result in better program retention and ultimately better weight loss results for people with class II and III obesity following a 
SERD. A more extensive study with a randomised design and a larger number of study participants is needed to confirm our results.

Supplementary Materials: The data presented in this study are available in https://www.mdpi. com/article/10.3390/obesities2010002/s1, File S1: Data.

Author Contributions: Individual author contributions are as follows: conceptualisation G.M., J.F. and E.M.; G.M. conducted descriptive statistics, H.R.K. conducted the statistical models and all authors substantially contributed to the interpretation of the data, curation and writing-original draft preparation G.M.; writing - review and editing, all authors substantially contributed; supervision, J.F., A.S., A.A.G., S.H. and T.P.M. All authors have read and agreed to the published version of the manuscript.

Funding: This work was supported by the National Health and Medical Research Council of Australia via a Senior Research Fellowship (1135897) to A.S.

Institutional Review Board Statement: The study was conducted according to the guidelines of the Declaration of Helsinki and approved by the Ethics Review Committee Royal Prince Alfred Hospital of the Sydney Local Health District on 7 September 2017 (LNR/18/CRGH/50).

Informed Consent Statement: Informed consent was obtained from all subjects involved in the study.

Data Availability Statement: The data presented in this study are available in Supplementary Materials.

Conflicts of Interest: A.S. reports owning 50\% of the shares in Zuman International, a company that receives income from educational materials and services on weight management and research methodology. A.S. also served on the Nestlé Health Science Optifast ${ }^{\circledR}$ VLCD ${ }^{\mathrm{TM}}$ Advisory Board from 2016-2018. T.M. has served on the Nestle Health Science VLCD Advisory Board since 2010. J.F. served on the Nestle Health Science VLCD Advisory Board between 2009-2013.

\section{References}

1. Ng, M.; Fleming, T.; Robinson, M.; Thomson, B.; Graetz, N.; Margono, C.; Mullany, E.C.; Biryukov, S.; Abbafati, C.; Abera, S.F.; et al. Global, regional, and national prevalence of overweight and obesity in children and adults during 1980-2013: A systematic analysis for the Global Burden of Disease Study 2013. Lancet 2014, 384, 766-781. [CrossRef]

2. OECD. Obesity Update 2017; OECD Health Statistics: Paris, France, 2017.

3. Asia Pacific Cohort Studies Collaboration. The burden of overweight and obesity in the Asia-Pacific region. Obes. Rev. 2007, 8 , 191-196. [CrossRef] [PubMed]

4. Palmo, A. Severe obesity: Introductory outlines and the conventional non surgical therapy. e-SPEN J. 2013, 8, e216-e227. [CrossRef]

5. Hubert, B.H.; Feinleib, M.M.; McNamara, P.P.; Castelli, P.W. Obesity as an Independent Risk Factor for Cardiovascular Disease: A 26-year Follow-up of Participants in the Framingham Heart Study. Circulation 1983, 67, 968-977. [CrossRef]

6. Lavie, C.J.; Milani, R.V.; Ventura, H.O. Obesity and Cardiovascular Disease: Risk Factor, Paradox, and Impact of Weight Loss. J. Am. Coll. Cardiol. 2009, 53, 1925-1932. [CrossRef]

7. Colditz, G.; Willett, W.C.; Rotnitzky, A.; Manson, J.E. Weight Gain as a Risk Factor for Clinical Diabetes Mellitus in Women. Ann. Intern. Med. 1995, 122, 481-486. [CrossRef] [PubMed]

8. Abdullah, A.; Peeters, A.; de Courten, M.; Stoelwinder, J. The magnitude of association between overweight and obesity and the risk of diabetes: A meta-analysis of prospective cohort studies. Diabetes Res. Clin. Pract. 2010, 89, 309-319. [CrossRef]

9. Boland, L.L.; Folsom, A.R.; Rosamond, W.D. Hyperinsulinemia, Dyslipidemia, and Obesity as Risk Factors for Hospitalized Gallbladder Disease: A Prospective Study. Ann. Epidemiol. 2002, 12, 131-140. [CrossRef]

10. Kovesdy, C.P.; Furth, S.L.; Zoccali, C.; Li, P.K.T.; Garcia-Garcia, G.; Benghanem-Gharbi, M.; Bollaert, R.; Dupuis, S.; Erk, T.; Kalantar-Zadeh, K.; et al. Obesity and kidney disease: Hidden consequences of the epidemic. Kidney Int. 2016, 91, 260-262. [CrossRef] [PubMed]

11. Gami, A.S.; Hodge, D.O.; Herges, R.M.; Olson, E.J.; Nykodym, J.; Kara, T.; Somers, V.K. Obstructive Sleep Apnea, Obesity, and the Risk of Incident Atrial Fibrillation. J. Am. Coll. Cardiol. 2007, 49, 565-571. [CrossRef] [PubMed]

12. Fang, X.; Wei, J.; He, X.; Lian, J.; Han, D.; An, P.; Zhou, T.; Liu, S.; Wang, F.; Min, J. Quantitative association between body mass index and the risk of cancer: A global Meta-analysis of prospective cohort studies. Int. J. Cancer 2018, 143, 1595-1603. [CrossRef] [PubMed]

13. Luppino, F.S.; de Wit, L.M.; Bouvy, P.F.; Stijnen, T.; Cuijpers, P.; Penninx, B.W.; Zitman, F.G. Overweight, Obesity, and Depression: A Systematic Review and Meta-analysis of Longitudinal Studies. Arch. Gen. Psychiatry 2010, 67, 220-229. [CrossRef]

14. Wilkes, S.; Fankam, F. Review of the management of female infertility: A primary care perspective. Clin. Med. Rev. Women's Health 2010, 2010, 11-23. 
15. Laberge, M.A.; Baum, T.; Virayavanich, W.; Nardo, L.; Nevitt, M.C.; Lynch, J.; McCulloch, C.E.; Link, T.M. Obesity increases the prevalence and severity of focal knee abnormalities diagnosed using 3T MRI in middle-aged subjects-Data from the Osteoarthritis Initiative. Skelet. Radiol. 2011, 41, 633-641. [CrossRef] [PubMed]

16. Lean, M.E.J.; Leslie, W.S.; Barnes, A.C.; Brosnahan, N.; Thom, G.; McCombie, L.; Peters, C.; Zhyzhneuskaya, S.; Al-Mrabeh, A.; Hollingsworth, K.G.; et al. Durability of a primary care-led weight-management intervention for remission of type 2 diabetes: 2-year results of the DiRECT open-label, cluster-randomised trial. Lancet Diabetes Endocrinol. 2019, 7, 344-355. [CrossRef]

17. Lean, M.E.; Leslie, W.S.; Barnes, A.C.; Brosnahan, N.; Thom, G.; McCombie, L.; Peters, C.; Zhyzhneuskaya, S.; Al-Mrabeh, A.; Hollingsworth, K.G.; et al. Primary care-led weight management for remission of type 2 diabetes (DiRECT): An open-label, cluster-randomised trial. Lancet 2018, 391, 541-551. [CrossRef]

18. Macmohan, S.; Cutler, J.; Brittain, E.; Higgins, M. Obesity and hypertension: Epidemiological and clinical issues. Eur. Heart J. 1987, 8, 57-70. [CrossRef]

19. Rothberg, A.E.; McEwen, L.N.; Kraftson, A.T.; Ajluni, N.; Fowler, C.E.; Nay, C.K.; Miller, N.M.; Burant, C.F.; Herman, W.H. Impact of weight loss on waist circumference and the components of the metabolic syndrome. BMJ Open Diabetes Res. Care 2017, 5, e000341. [CrossRef] [PubMed]

20. Dattilo, A.M.; Kris-Etherton, P.M. Effects of weight reduction on blood lipids and lipoproteins: A meta-analysis. Am. J. Clin. Nutr. 1992, 56, 320-328. [CrossRef]

21. Huffman, D.M.; Barzilai, N. Contribution of Adipose Tissue to Health Span and Longevity. Interdiscip. Top. Gerontol. 2010, 37, 1-19. [CrossRef]

22. Finelli, C.; Sommella, L.; Gioia, S.; La Sala, N.; Tarantino, G. Should visceral fat be reduced to increase longevity? Ageing Res. Rev. 2013, 12, 996-1004. [CrossRef]

23. Seimon, R.V.; Wild-Taylor, A.L.; McClintock, S.; Harper, C.; Gibson, A.A.; Johnson, N.A.; Fernando, H.A.; Markovic, T.P.; Center, J.R.; Franklin, J.; et al. 3-Year effect of weight loss via severe versus moderate energy restriction on body composition among postmenopausal women with obesity-The TEMPO Diet Trial. Heliyon 2020, 6, e04007. [CrossRef] [PubMed]

24. Astbury, N.M.; Piernas, C.; Hartmann-Boyce, J.; Lapworth, S.; Aveyard, P.; Jebb, S.A. A systematic review and meta-analysis of the effectiveness of meal replacements for weight loss. Obes. Rev. 2019, 20, 569-587. [CrossRef]

25. Gibson, A.A.; Seimon, R.V.; Franklin, J.; Markovic, T.P.; Byrne, N.M.; Manson, E.; Caterson, I.D.; Sainsbury, A. Fast versus slow weight loss: Development process and rationale behind the dietary interventions for the TEMPO Diet Trial. Obes. Sci. Pract. 2016, 2, 162-173. [CrossRef]

26. Codex Alimentarius Commission. Report of the Nineteenth Sesssion of the Codex Committee on Nutrition and Foods for Special Dietary Uses; Joint FAO/WHO Food Standards Program; Codex Alimentarius Commission: Bad Godesberg, Germany; Rome, Italy, 1995.

27. Kizirian, N.A.S.; Colagiuri, S.; Deed, G.; Proietto, J.; Dixon, J.; Markovic, T.; Hamdorf, J.; Rigas, G. The Australian Obesity Management Algorithm; The University of Sydney: Sydney, Australia, 2016.

28. Maston, G.; Gibson, A.A.; Kahlaee, H.R.; Franklin, J.; Manson, E.; Sainsbury, A.; Markovic, T.P. Effectiveness and characterization of severely energy-restricted diets in people with extreme obesity: Systematic review and meta-analysis. Behav. Sci. 2019, 9, 144. [CrossRef]

29. Phelan, S.; Wing, R.R.; Brannen, A.; McHugh, A.; Hagobian, T.A.; Schaffner, A.; Jelalian, E.; Hart, C.N.; Scholl, T.O.; MunozChristian, K.; et al. Randomized controlled clinical trial of behavioral lifestyle intervention with partial meal replacement to reduce excessive gestational weight gain. Am. J. Clin. Nutr. 2018, 107, 183-194. [CrossRef]

30. Maston, G.; Franklin, J.; Gibson, A.A.; Manson, E.; Hocking, S.; Sainsbury, A.; Markovic, T.P. Attitudes and Approaches to Use of Meal Replacement Products among Healthcare Professionals in Management of Excess Weight. Behav. Sci. 2020, 10, 136. [CrossRef]

31. Noakes, M.; Foster, P.R.; Keogh, J.; Clifton, P. Meal Replacements Are as Effective as Structured Weight-Loss Diets for Treating Obesity in Adults with Features of Metabolic Syndrome. J. Nutr. 2004, 134, 1894-1899. [CrossRef]

32. Wright, G.; Dawson, B.; Jalleh, G.; Law, S. Impact of compliance on weight loss and health profile in a very low energy diet program. Aust. Fam. Physician 2010, 39, 49-52. [PubMed]

33. Steven, S.; Hollingsworth, K.G.; Al-Mrabeh, A.; Avery, L.; Aribisala, B.; Caslake, M.; Taylor, R. Very Low-Calorie Diet and 6 Months of Weight Stability in Type 2 Diabetes: Pathophysiological Changes in Responders and Nonresponders. Diabetes Care 2016, 39, 808-815. [CrossRef] [PubMed]

34. Rehackova, L.; Araújo-Soares, V.; Adamson, A.; Steven, S.; Taylor, R.; Sniehotta, F.F. Acceptability of a very-low-energy diet in Type 2 diabetes: Patient experiences and behaviour regulation. Diabet. Med. 2017, 34, 1554-1567. [CrossRef]

35. Maston, G.; Franklin, J.; Hocking, S.; Swinbourne, J.; Gibson, A.; Manson, E.; Sainsbury, A.; Markovic, T. Dietary adherence and program attrition during a severely energy-restricted diet among people with complex class III obesity: A qualitative exploration. PLoS ONE 2021, 16, e0253127. [CrossRef] [PubMed]

36. Mustajoki, P.; Pekkarinen, T. Very low energy diets in the treatment of obesity. Obes. Rev. 2001, 2, 61-72. [CrossRef] [PubMed]

37. Miller, W.R. Motivational Interviewing: Helping People Change, 3rd ed.; Rollnick, S., Ed.; Guilford Publications: New York, NY, USA, 2012

38. National Health and Medical Research Council. Nutrient Reference Values Australia and New Zealand; Australian Government: Canberra, Australia, 2006 
39. Gibson, A.A.; Franklin, J.; Pattinson, A.L.; Cheng, Z.G.Y.; Samman, S.; Markovic, T.P.; Sainsbury, A. Comparison of Very Low Energy Diet Products Available in Australia and How to Tailor Them to Optimise Protein Content for Younger and Older Adult Men and Women. Healthcare 2016, 4, 71. [CrossRef]

40. National Health and Medical Research Council. Australian Dietary Guidelines; National Health and Medical Research Council: Canberra, Australia, 2013.

41. Food Standards Australia New Zealand. Australian Food Composition Database Food Standards Australia New Zealand. Food Standards Australia New Zealand, 2019. Available online: https:/ /www.foodstandards.gov.au/science/monitoringnutrients/ afcd/Pages/default.aspx (accessed on 1 November 2019).

42. Jésus, P.; Achamrah, N.; Grigioni, S.; Charles, J.; Rimbert, A.; Folope, V.; Petit, A.; Déchelotte, P.; Coëffier, M. Validity of predictive equations for resting energy expenditure according to the body mass index in a population of 1726 patients followed in a Nutrition Unit. Clin. Nutr. 2015, 34, 529-535. [CrossRef]

43. National Health and Medical Research Council. Clinical Practice Guidelines for the Management of Overweight and Obesity in Adults, Adolescents and Children in Australia; Australian Government: Canberra, Australia, 2013.

44. Expert Panel on the Treatment of Obesity in Adults. Clinical guidelines on the identification, evaluation, and treatment of overweight and obesity in adults: Executive summary. Am. J. Clin. Nutr 1998, 68, 899-917.

45. Scottish Intercollegiate Guidelines Network. Management of Obesity: SIGN Guideline 115; Scottish Intercollegiate Guidelines Network: Edinburgh, UK, 2010.

46. National Institute for Health and Care Excellence. Weight Management: Lifestyle Services for Overweight or Obese Adults; National Institute for Health and Care Excellence: London, UK, 2014.

47. Kanerva, N.; Larsson, I.; Peltonen, M.; Lindroos, A.-K.; Carlsson, L.M. Changes in total energy intake and macronutrient composition after bariatric surgery predict long-term weight outcome: Findings from the Swedish Obese Subjects (SOS) study. Am. J. Clin. Nutr. 2017, 106, 136-145. [CrossRef]

48. Zomer, E.; Gurusamy, K.; Leach, R.; Trimmer, C.; Lobstein, T.; Morris, S.; James, W.; Finer, N. Interventions that cause weight loss and the impact on cardiovascular risk factors: A systematic review and meta-analysis. Obes. Rev. 2016, 17, 1001-1011. [CrossRef]

49. Ashtary-Larky, D.; Ghanavati, M.; Lamuchi-Deli, N.; Payami, S.A.; Alavi-Rad, S.; Boustaninejad, M.; Afrisham, R.; Abbasnezhad, A.; Alipour, M. Rapid Weight Loss vs. Slow Weight Loss: Which is More Effective on Body Composition and Metabolic Risk Factors? Int. J. Endocrinol. Metab. 2017, 15, e13249. [CrossRef]

50. Anderson, J.W.; Grant, L.; Gotthelf, L.; Stifler, L.T. Weight loss and long-term follow-up of severely obese individuals treated with an intense behavioral program. Int. J. Obes. 2007, 31, 488-493, Erratum in Int. J. Obes. 2007, 31, 565. [CrossRef] [PubMed]

51. Harbury, C.M.; Verbruggen, E.E.; Callister, R.; Collins, C.E. What do individuals with morbid obesity report as a usual dietary intake? A narrative review of available evidence. Clin. Nutr. ESPEN 2016, 13, e15-e22. [CrossRef]

52. Strain, G.W.; Hershcopf, R.J.; Zumoff, B. Food-intake of very obese persons-Quantitative and qualitative aspects. J. Am. Diet. Assoc. 1992, 92, 199-203. [CrossRef]

53. Micha, R.; Khatibzadeh, S.; Shi, P.; Andrews, K.G.; Engell, R.E.; Mozaffarian, D. Global, regional and national consumption of major food groups in 1990 and 2010: A systematic analysis including 266 country-specific nutrition surveys worldwide. BMJ Open 2015, 5, e008705. [CrossRef]

54. Buijsse, B.; Feskens, E.; Schulze, M.B.; Forouhi, N.; Wareham, N.J.; Sharp, S.; Palli, D.; Tognon, G.; Halkjaer, J.; Tjonneland, A.; et al. Fruit and vegetable intakes and subsequent changes in body weight in European populations: Results from the project on Diet, Obesity, and Genes (DiOGenes). Am. J. Clin. Nutr. 2009, 90, 202-209. [CrossRef] [PubMed]

55. He, K.; Hu, F.B.; Colditz, G.; Manson, J.E.; Willett, W.C.; Liu, S. Changes in intake of fruits and vegetables in relation to risk of obesity and weight gain among middle-aged women. Int. J. Obes. 2004, 28, 1569-1574. [CrossRef] [PubMed]

56. Franz, M.J.; VanWormer, J.J.; Crain, A.L.; Boucher, J.L.; Histon, T.; Caplan, W.; Bowman, J.D.; Pronk, N.P. Weight-Loss Outcomes: A Systematic Review and Meta-Analysis of Weight-Loss Clinical Trials with a Minimum 1-Year Follow-Up. J. Am. Diet. Assoc. 2007, 107, 1755-1767. [CrossRef] [PubMed]

57. King, B.M.; Cespedes, V.M.; Burden, G.K.; Brady, S.K.; Clement, L.R.; Abbott, E.M.; Baughman, K.S.; Joyner, S.E.; Clark, M.M.; Pury, C.L.S. Extreme under-reporting of body weight by young adults with obesity: Relation to social desirability. Obes. Sci. Pract. 2018, 4, 129-133. [CrossRef]

58. Dekkers, J.C.; Van Wier, M.F.; Hendriksen, I.J.M.; Twisk, J.W.R.; Van Mechelen, W. Accuracy of self-reported body weight, height and waist circumference in a Dutch overweight working population. BMC Med. Res. Methodol. 2008, 8, 69. [CrossRef]

59. Park, H.A.; Lee, J.S.; Kuller, L.H. Underreporting of dietary intake by body mass index in premenopausal women participating in the Healthy Women Study. Nutr. Res. Pract. 2007, 1, 231-236. [CrossRef] 